\title{
Characterization of wheat varieties (Triticum spp.) through seed morphology
}

\author{
J. B. Patel*, J. D. Ukani, C. A. Babariya and P. S. Ramani \\ Department of Seed Science and Technology, College of Agriculture, Junagadh Agricultural University, Junagadh \\ - 362001 (Gujarat), INDIA \\ *Corresponding author. E-mail: jbpatelvasai38@gmail.com
}

Received: September 10, 2015; Revised received: January 1, 2016; Accepted: March 21, 2016

\begin{abstract}
An experiment was carried out at the Department of Seed Science and Technology, Junagadh Agricultural University, Junagadh, to characterize 28 wheat varieties of different species [17 varieties (MP 4010, HI 1500, HI 1531, HI 1544, GW 1, GW 503, DL 788-2, HD 2932, GW 11, GW 173, GW 190, GW 273, LOK 1, GW 322, MP 3288, GW 366 and GW 496) of Triticum aestivum, 9 varieties (HI 8381, HI 8498, HI 8627, HI 8713, A 28, A 206, GDW 1255, GW 1139 and RAJ 1555) of Triticum durum and 2 varieties (DDK 1025, DDK 1029) of Triticum dicoccum)] released for general cultivation in Gujarat at state level as well as at the National level in Central India based on the seed morphological characters. Based on the seed colour, the varieties were grouped into amber (25), white (1) and red (2). On the basis of seed shape, wheat varieties were separated in to round (2) ovate (7), oblong (12) and elliptical (7). On the basis of seed size, varieties were grouped into medium seed size (5), bold seed size (15) and very bold seed size (8). On the basis of seed hardness, varieties were grouped into soft (1), semi-hard (7) and hard (20). Based on the seed germ width, varieties were grouped into medium (15), wide (9) and narrow (4) seed germ width types. The varieties were grouped based on the seed crease into three groups, as medium (11), shallow (12) and deep (5) grain crease types. Based on the brush hair length, wheat varieties were grouped as short (17), medium (7) and long (4) brush hair length types.
\end{abstract}

Keywords: Characterization, Morphology, Seed, T. aestivum, T. dicoccum, T. durum, Wheat

\section{INTRODUCTION}

Wheat is one of the most important and widely cultivated crops in the world, used mainly for human consumption and support nearly $35 \%$ of the world population (Mohammadi-joo et al., 2015) and providing 20 per cent of the total food calories (Anonymous, 2014). It is the most widely cultivated food crop of the world. It is known for its remarkable adoption to a wide range of environments and its role in world economy. The main wheat growing countries are European Union, China, India, USA, Russian Federation, Canada, Australia, Pakistan, Turkey, Ukraine, Iran, (Anonymous, 2015).

Wheat (Triticum spp. L.) is an annual plant that belongs to the grass family Poaceae, tribe Triticeae, and subtribe Triticineae. It is thought to have originated on the Eurasian continent, a starting point from which man spread it throughout the world, including China and central Europe (Haider, 2012). Wheat is one of the earliest domesticated crop plants in the Pre-Pottery Neolithic Near East (Lev-Yadun et al., 2000). The center of its domestication is widely accepted to be somewhere in the Middle East (Anikster and Wahl, 1979). It is the world's most widely cultivated food crop, followed by rice and maize (GulbittiOnarici et al., 2009), and one of the oldest and most important of the cereal crops (Harlan, 1992), produc- ing the highest global grain production of any crop (Lamoureux et al., 2005).

In India, wheat is mainly grown in the states of Uttar Pradesh, Madhya Pradesh, Punjab, Rajasthan, Haryana, Bihar, Maharashtra, Karnataka and Gujarat. During 2013-14, India accounts an area, production and productivity of 31.34 million ha, 95.91 million metric tonnes and $3061 \mathrm{~kg} / \mathrm{ha}$, respectively (Anonymous, 2013). In Gujarat, wheat is grown during 2013-14 in about 13.51 lac ha with total production of 36.50 lac metric tonnes and productivity of $2074 \mathrm{~kg} / \mathrm{ha}$ (Anonymous, 2013). Globally, demand for wheat by the year 2020 is forecast at around 950 million tonnes per year. This target will be achieved only, if global wheat production is increased approximately by 2.5 per cent per annum.

Maintenance of genetic purity of varieties is of primary importance for preventing varietal deterioration during successive regeneration cycles and for ensuring varietal performance at an expected level. The aspects of Distinctness, Uniformity and Stability (DUS) are fundamental for characterization of varieties. In countries having Plant Breeder's Right (PBR) in operation, a new variety is registered only, if it is distinct from other varieties, uniform in its characteristics and genetically stable. In the light of the above facts, the present study on documentation of characters 
for wheat varieties was planned with the objective to identify stable diagnostic characteristics of seed morphology of wheat varieties.

\section{MATERIALS AND METHODS}

The experiment was conducted in the seed testing laboratory of Department of Seed Science and Technology, Junagadh Agricultural University, Junagadh, during rabi 2014 to study the varietal characterization in 28 wheat varieties [17 varieties (MP 4010, HI 1500, HI 1531, HI 1544, GW 1, GW 503, DL 788-2, HD 2932, GW 11, GW 173, GW 190, GW 273, LOK 1, GW 322, MP 3288, GW 366 and GW 496) of Triticum aestivum, 9 varieties (HI 8381, HI 8498, HI 8627, HI 8713, A 28, A 206, GDW 1255, GW 1139 and RAJ 1555) of Triticum durum and 2 varieties (DDK 1025, DDK 1029) of Triticum dicoccum)] released for general cultivation in Gujarat at state level as well as at the national level in central India based on the seed morphological characters. Seed morphological characters viz., seed colour, seed shape, seed size (test weight) (g), seed hardness, seed germ width, seed crease and brush hair length were measured as per the guidelines of DUS testing (http://plantauthority.gov.in/ pdf/GBread\%20 Wheat.pdf). Of all the seed morphological characters, seed size (test weight) was the only quantitative character, which was analyzed following analysis of variance for Completely Randomized Design as per the method of Cochran and Cox (1957)

\section{RESULTS AND DISCUSSION}

Based on the variation in seed morphological characteristics, the varieties were grouped in to different categories (Table 1 and 2). Based on the seed colour, the varieties were grouped into amber (25 varieties), white (1 variety) and red (2 varieties). On the basis of seed shape, wheat varieties were separated in to round (2 varieties) ovate (7 varieties), oblong (12 varieties) and elliptical (7 varieties). On the basis of seed size, five varieties were grouped into medium seed size (35-40 $\mathrm{g})$, fifteen in bold seed size (40-45 g) and eight in very bold seed size $(>45 \mathrm{~g})$. The seed size ranged from $35.78 \mathrm{~g}$ (GW 190) to $54.62 \mathrm{~g}$ (LOK 1) with a mean of $43.66 \mathrm{~g}$. On the basis of seed hardness, one genotype was grouped as soft, seven varieties as semi-hard and twenty varieties as hard. Based on the seed germ width, fifteen varieties were grouped as medium, nine varieties as wide and four varieties as narrow seed germ width types. The varieties were grouped based on the seed crease into three groups, as medium (11 varieties), shallow (12 varieties) and deep (5e varieties) seed crease types. Based on the brush hair length, seventeen varieties were grouped as short, seven varieties as medium and four varieties as long brush hair length types.

The seed morphological characteristics helped in identifying and grouping of the varieties. Based on the variation in seed morphological characteristics, wheat
Table 1. Identification and grouping of wheat varieties based on seed colour, seed shape and seed size (test weight).

\begin{tabular}{|c|c|c|c|c|}
\hline Varieties & $\begin{array}{l}\text { Seed } \\
\text { Colour }\end{array}$ & $\begin{array}{l}\text { Seed } \\
\text { Shape }\end{array}$ & $\begin{array}{l}\text { Seed Size } \\
\text { (Test } \\
\text { Weight }(\mathrm{g})\end{array}$ & $\begin{array}{l}\text { Groups } \\
\text { (Seed } \\
\text { Size) } \\
\end{array}$ \\
\hline \multicolumn{5}{|c|}{ Triticum aestivum $\mathrm{L}$. } \\
\hline MP 4010 & Amber & Oblong & 43.31 & Bold \\
\hline HI 1500 & Amber & Oblong & 44.21 & Bold \\
\hline HI 1531 & Amber & Round & 38.62 & Medium \\
\hline HI 1544 & Amber & Round & 40.71 & Bold \\
\hline GW 1 & Amber & Elliptical & 42.82 & Bold \\
\hline GW 503 & Amber & Oblong & 42.51 & Bold \\
\hline DL 788-2 & Amber & Oblong & 42.06 & Bold \\
\hline HD 2932 & Amber & Elliptical & 41.43 & Bold \\
\hline GW 11 & Amber & Ovate & 47.37 & Very bold \\
\hline GW 173 & Amber & Oblong & 39.30 & Medium \\
\hline GW 190 & Amber & Ovate & 35.78 & Medium \\
\hline GW 273 & Amber & Ovate & 40.18 & Bold \\
\hline LOK 1 & Amber & Oblong & 54.62 & Very bold \\
\hline GW 322 & Amber & Ovate & 38.32 & Medium \\
\hline MP 3288 & White & Oblong & 39.81 & Medium \\
\hline GW 366 & Amber & Ovate & 48.59 & Very bold \\
\hline GW 496 & Amber & Ovate & 42.58 & Bold \\
\hline \multicolumn{5}{|c|}{ Triticum durum Desf } \\
\hline HI 8381 & Amber & Elliptical & 44.45 & Bold \\
\hline HI 8498 & Amber & Oblong & 51.91 & Very bold \\
\hline HI 8627 & Amber & Elliptical & 42.03 & Bold \\
\hline HI 8713 & Amber & Ovate & 43.97 & Bold \\
\hline A 28 & Amber & Oblong & 41.81 & Bold \\
\hline A 206 & Amber & Oblong & 44.51 & Bold \\
\hline GDW & Amber & Elliptical & 46.21 & Very bold \\
\hline \multicolumn{5}{|l|}{1255} \\
\hline GW 1139 & Amber & Oblong & 47.13 & Very bold \\
\hline RAJ & Amber & Oblong & 48.94 & Very bold \\
\hline 1555 & & & & \\
\hline \multicolumn{5}{|c|}{ Triticum dicoccum Schrank } \\
\hline \multicolumn{5}{|c|}{$\begin{array}{lll}\text { DDK } & \text { Red } & \text { Elliptical }\end{array}$} \\
\hline \multicolumn{5}{|l|}{1025} \\
\hline DDK & Red & Elliptical & 45.12 & Very bold \\
\hline \multicolumn{5}{|l|}{1029} \\
\hline Mean & & & 43.66 & \\
\hline S.Em \pm & & & 0.37 & \\
\hline C.D. at 5 & & & 1.05 & \\
\hline \multicolumn{5}{|l|}{$\%$} \\
\hline CV \% & & & 1.46 & \\
\hline
\end{tabular}

Note: Seed Size (Test weight) g; Low $<35 \mathrm{~g}$; Medium 35 to $40 \mathrm{~g}$; Bold 40 to $45 \mathrm{~g}$; Very bold $>45 \mathrm{~g}$.

varieties identification keys are presented in Fig. 1. The varieties viz., MP 4010 and GW 503 were having similar seed morphology viz., amber seed colour, oblong seed shape, bold seed size, hard seed, medium seed germ width, shallow seed crease and medium brush hair length. The varieties, HI-1500 and DL-7882 were differing from the above varieties (MP 4010 and GW 503) with respect to brush hair length having short brush hair length, while GW 173 with respect to seed size having medium size seed. The variety, A 28 was having amber seed colour, oblong seed shape, bold seed size, hard seed, wide seed germ width, deep seed crease and medium brush hair length and was varied with A 206 with respect to medium seed crease. The varieties, LOK 1, HI 8498, GW 1139 and RAJ 
Table 2. Identification and grouping of wheat varieties based on seed hardness, seed germ width, seed crease and brush hair length.

\begin{tabular}{|c|c|c|c|c|}
\hline Varieties & $\begin{array}{l}\text { Seed } \\
\text { Hardness }\end{array}$ & $\begin{array}{l}\text { Seed } \\
\text { Germ } \\
\text { Width }\end{array}$ & $\begin{array}{l}\text { Seed } \\
\text { Crease }\end{array}$ & $\begin{array}{l}\text { Brush } \\
\text { Hair } \\
\text { Length }\end{array}$ \\
\hline \multicolumn{5}{|c|}{ Triticum aestivum $\mathrm{L}$. } \\
\hline MP 4010 & Hard & Medium & Shallow & Medium \\
\hline HI 1500 & Hard & Medium & Shallow & Short \\
\hline HI 1531 & Semi hard & Narrow & Shallow & Short \\
\hline HI 1544 & Semi hard & Wide & Shallow & Short \\
\hline GW 1 & Hard & Wide & $\begin{array}{l}\text { Deep } \\
\text { crease }\end{array}$ & Medium \\
\hline GW 503 & Hard & Medium & Shallow & Medium \\
\hline DL 788-2 & Hard & Medium & Shallow & Short \\
\hline HD 2932 & Hard & Medium & Medium & Short \\
\hline GW 11 & Semi hard & Medium & Medium & Short \\
\hline GW 173 & Hard & Medium & Shallow & Short \\
\hline GW 190 & Semi hard & Medium & $\begin{array}{l}\text { Deep } \\
\text { crease }\end{array}$ & Long \\
\hline GW 273 & Hard & Narrow & Medium & Short \\
\hline LOK 1 & Hard & Medium & Medium & Medium \\
\hline GW 322 & Semi hard & Wide & Shallow & Long \\
\hline MP 3288 & Hard & Medium & Medium & Short \\
\hline GW 366 & Hard & Medium & Medium & Short \\
\hline GW 496 & Semi hard & Medium & Shallow & Medium \\
\hline \multicolumn{5}{|c|}{ Triticum durum Desf } \\
\hline HI 8381 & Hard & Medium & Medium & Short \\
\hline HI 8498 & Hard & Wide & Shallow & Short \\
\hline HI 8627 & Hard & Wide & Shallow & Short \\
\hline HI 8713 & Hard & Wide & Medium & Short \\
\hline A 28 & Hard & Wide & Medium & Medium \\
\hline A 206 & Hard & Wide & $\begin{array}{l}\text { Deep } \\
\text { crease }\end{array}$ & Medium \\
\hline $\begin{array}{l}\text { GDW } \\
1255\end{array}$ & Hard & Medium & $\begin{array}{l}\text { Deep } \\
\text { crease }\end{array}$ & Short \\
\hline GW 1139 & Hard & Medium & Medium & Short \\
\hline RAJ 1555 & Hard & Wide & Medium & Short \\
\hline \multicolumn{5}{|c|}{ Triticum dicoccum Schrank } \\
\hline $\begin{array}{l}\text { DDK } \\
1025\end{array}$ & Soft & Narrow & $\begin{array}{l}\text { Deep } \\
\text { crease }\end{array}$ & Long \\
\hline $\begin{array}{l}\text { DDK } \\
1029\end{array}$ & Semi hard & Narrow & Shallow & Long \\
\hline
\end{tabular}

1555 were having amber seed colour, oblong seed shape, very bold seed size and hard seed, but were distinct to each other with respect to germ width, seed crease and brush hair length. The LOK 1 was medium in seed germ width, seed crease and brush hair length, while HI 8498 having wide seed germ width, shallow seed crease and short brush hair length, GW 1139 having medium seed germ width, medium seed crease and short brush hair length and RAJ 1555 having wide seed germ width, medium seed crease and short brush hair length. MP 3288 is the only variety under study having white seed colour with oblong seed shape, medium seed size, hard seed, medium seed germ width, medium seed crease, short brush hair length. GW 11 and GW 366 were having amber seed colour, ovate seed shape, very bold seed size, medium seed germ width, medium seed crease and short brush hair length, but differing in seed hardness (GW 11 had semi hard seed, while GW 366 had hard seed). GW 273, GW 496 and HI 8713 were having amber seed colour, ovate seed shape, bold seed size and hard seed, but differing to each other with respect to seed germ width, seed crease and brush hair length. GW 273 was having narrow seed germ width, medium seed crease and short brush hair length, while GW 496 was having medium seed germ width, shallow seed crease, medium brush hair length and HI 8713 having wide seed germ width, medium seed crease, short brush hair length. GW 322 was having amber seed colour, ovate seed shape, medium seed size, semi hard seed, wide seed germ width, shallow seed crease and long brush hair length. HI 1531 and HI 1544 were having amber seed colour, round seed shape, semi hard seed, shallow seed crease and short brush hair length, but differing in seed size and seed germ width. HI 1531 had medium size seed with narrow seed germ width, while HI 1544 had bold seed with wide seed germ width.

HI 2932 and HI 8381 were having amber seed colour, elliptical seed shape, bold seed size, hard seed, medium seed germ width, medium seed crease and short brush hair length. Two varieties, GW 1 and HI 8627 were differing from the HI 2932 and HI 8381 with respect to seed germ width, seed crease and brush hair length. GW1 having wide seed germ width, deep seed crease and medium brush hair length, while HI 8627 having wide seed germ width, shallow seed crease and short brush hair length.

GDW 1255 was having amber seed colour, elliptical seed shape, very bold seed size, hard seed, medium seed germ width, deep seed crease and short brush hair length, whereas GW 190 was having amber seed colour, ovate seed shape, very bold seed size, semi hard seed, medium seed germ width, deep seed crease and long brush hair length. Similarly, variety DDK-1025 was having red seed colour, elliptical seed shape, bold seed size, soft seed, narrow seed germ width, deep seed crease and long brush hair length, while DDK 1029 having red seed colour, elliptical seed shape, very bold seed size, semi hard seed, narrow seed germ width, shallow seed crease and long brush hair length. In nut shell, MP 4010 and GW 503, HI 1500 and DL 788-2 and HD 2932 and HI 8381 possessed the similar seed morphology and cannot be differentiated from each other on the basis of seed characteristics. All the remaining 22 varieties were differed from other varieties under study at least for one seed character and could be helpful for the identification of variety from the seed lot.

Similar observations and grouping of varieties based on seed morphological characters were made by various scientists in past in wheat. Naseem et al. (2007) characterized 12 buckwheat varieties/genotypes using seed parameters viz., seed coat colour, seed shape and seed weight. Among these, seed shape was found to be the most effective parameter for characterization of buckwheat cultivars. The cultivar Shimla B1 had 


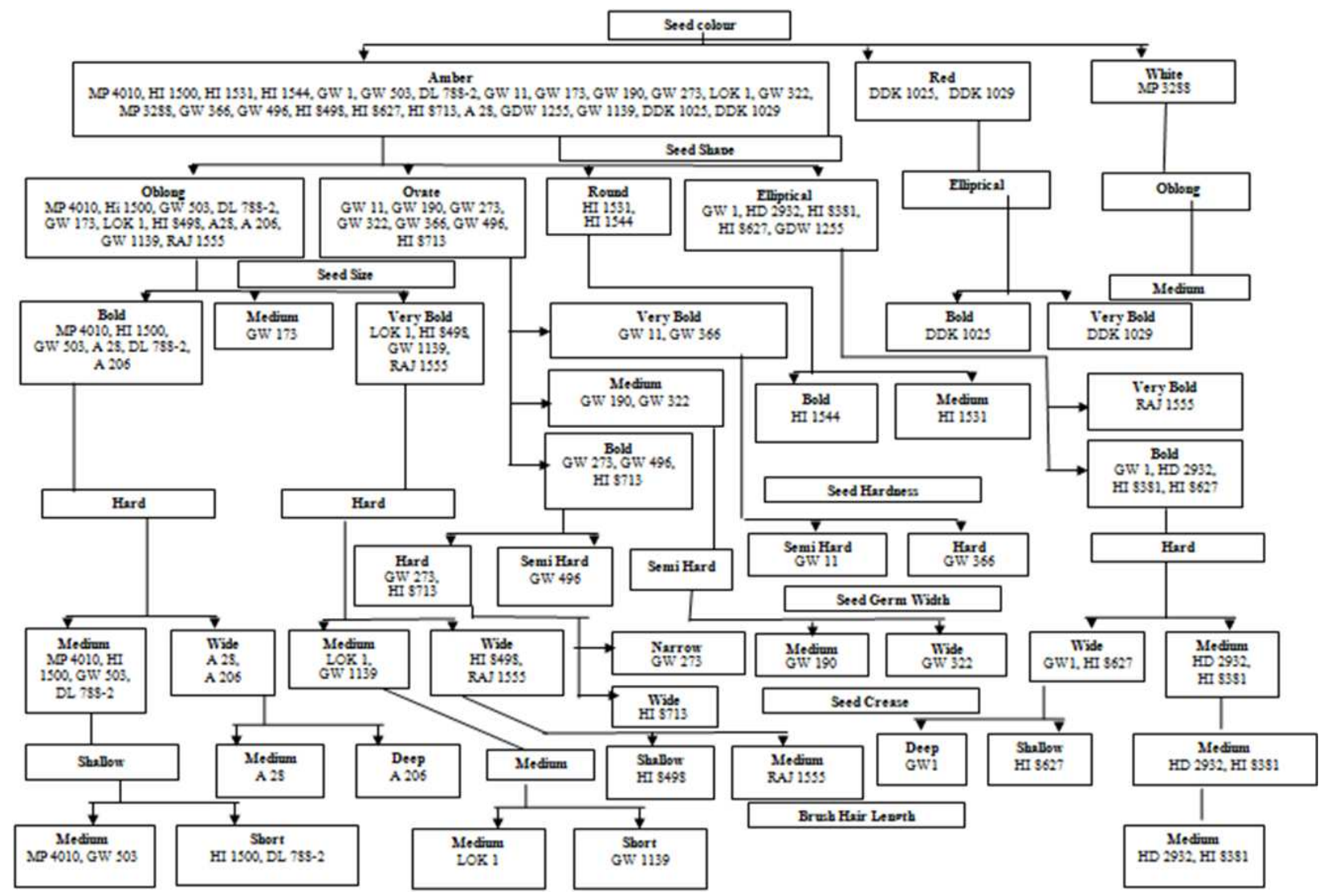

Fig. 1. Wheat varieties identification keys on the basis of seed morphological characters.

slightly ovate seed shape and differed from all other cultivars that had conical or triangular seed shape. The cultivar Sangla B2 and Shimla B2 had black seed coat colour, VL 7 and PRB 1 had mottled and the rest showed grey seed colour. Khan et al. (2009) observed significantly, the highest test weight in grains of wheat variety C $273(78.00 \mathrm{~kg} / \mathrm{hl})$ followed by Iqbal 2000 $(76.90 \mathrm{~kg} / \mathrm{hl})$. The grains of Kohinoor 83 yielded significantly the lowest test weight $(66.47 \mathrm{~kg} / \mathrm{hl})$. Mansing (2010) grouped the wheat genotypes based on seed morphology and reported that the seed morphological characteristics helped in identifying and grouping of the genotypes. The genotypes viz., DWR 162 and DWR 225 were having amber colour, ovate type seed shape, semi-hard in nature, low test weight, medium germ width and long brush hair length, while the genotype NI 5439 was distinct to above mentioned genotypes by having medium brush hair length. Similarly, the genotypes viz., DWR 185, MACS 2846 and NIDW 295 showed distinctness in seed characters by having oblong shape, hard in nature, very bold in test weight, wide in germ width and lacking in brush hair length. The genotypes viz., UAS 304 and UAS 305 showed similarity in characters by having amber coloured, oblong shaped, semi-hard in nature, bold in test weight, wide in germ width, but distinct only in brush hair length. Brush hair was absent in UAS 305. Whereas, the genotypes DDK 1001 and DDK 1009 were red in colour, elliptical in shape, hard in nature, medium in test weight, wide in germ width and long in brush hair length.

However, seed colour is genetically controlled characteristics, and it is influenced by the environment (Pascual-Villalobos et al., 1993) and thus, leading to difficulty in classifying the genotypes on the basis of seed colour.

\section{REFERENCES}

Anikster, Y. and Wahl, I. (1979). Co-evolution of the rust fungi on Gramineae and Liliaceae and their hosts. Annual Rev. Phytopathol., 17: 367-403.

Anonymous (2013). Wheat Scenario: A Snippet. $e$ newsletter 1 (2013), The Directorate of Wheat Research, Karnal, Haryana (India).

Anonymous (2014). http://www.theguardian.com/globaldevelopment-professionals-network/2014/apr/01/ international-wheat-yield- partnership-food-security

Anonymous (2015). Crop Prospectus and Food Situation. Food and Agriculture Organizarion of the United Nations. March 2015. 1: 1-42 (http://www.fao.org/3/ai4410e.pdf).

Cochran, W. G. and Cox, G. M. (1957). Experimental Designs. John Wiley and Sons, Inc. Chapman and Hall Limited, London.

Gulbitti-Onarici, S.; Sancak, C.; Sumer, S. and Ozcan, S. (2009). Phylogenetic relationships of some wild wheat species based on the internal transcribed spacer sequences of nrDNA. Curr. Sci., 96: 794-800.

Haider, N. (2012). Evidence for the origin of the B genome of bread wheat based on chloroplast DNA. Turk. J. 
Agric., 36: 13-25.

Harlan, J. R. (1992). Origin and Processes of Domestication. In: Grass Evolution and Domestication (Ed. GP Chapman). Cambridge University Press, Cambridge.

http://plantauthority.gov.in/pdf/GBread\%20Wheat.pdf

Khan, M. R.; Anjum, F. M.; Zahoor, T.; Tahir, Z. and Nawaz, H. (2009). Biochemical and technological characterization of Pakistani spring wheats. Pakistan J. Agri. Sci., 46(4): 271-279.

Lamoureux, D.; Peterson, D. G.; Li, W.; Fellers, J. P. and Gill, B. S. (2005).The efficacy of cost-based gene enrichment in wheat (Triticum aestivum L.). Genome, 48: 1120-1126

Lev-Yadun, S.; Gopher, A. and Abbo, S. (2000). The cradle of agriculture. Sci., 288: 1602-1603.

Mansing, J. S. (2010). Characterization of wheat (Triticum spp.) genotypes trough morphological, chemical and molecular markers. M.Sc. (Agri.) thesis (Unpublished) submitted to University of Agricultural Sciences, Dharwad.

Mohammadi-joo, S.; Mirasi, A.; Saeidi-aboeshaghi, R. and Amiri, M. (2015). Evaluation of bread wheat (Triticum aestivum L.) genotypes based on resistance indices under field conditions. Int. J. Biosci., 6(2): 331-337.

Naseem, M.; Dutta, M.; Shah, Shachi and Kumar, P. (2007). Characterization of buckwheat cultivars using morphological, chemical, physiological and biochemical parameters. Proc. $10^{\text {th }}$ International Sympo. Buckwheat, G. B. Pant University of Agriculture \& Technology, Hill Campus, Ranichauri, Tehri Garhwal, Uttarakhand, India.

Pascual-Villalobos, M. J.; Oritz, J. M. and Coorreal, E. (1993). Morphological characterization of seeds of $\mathrm{Eu}$ phorbia lagascae. Seed Sci. Technol., 21: 53-60. 